\title{
International Whaling: Eating the Seed Corn
}

\author{
Richard Fitter
}

In reporting on the 1976 meeting of the International Whaling Commission, held in London from June 21-25, it may be worth quoting the statement of the FPS position which I made to the Commission at the start of the proceedings:

'A resolution of the 12th General Assembly of IUCN meeting in Kinshasa, Zaire, in September 1975, urged that the concept of maximum sustainable yield (MSY) as a basis for management of wildlife resources should be replaced. The Fauna Preservation Society fully supports this resolution.

'The continuing decline in the size of sperm whales illustrates the failings of MSY concepts. The whaling quotas were set numerically and did not take into account the catastrophic decline in the biomass of the catch, up to two-thirds over the past twenty years. This is both bad science and bad economics. We urge that future quotas for all cetaceans be set according to the principles outlined at Kinshasa and that these principles are adopted now - not deferred for another year.

'Increasing concern is being shown about the stocks of small whales. Although virtually nothing is known about their populations a large and unregulated catch forms a significant proportion of the world cetacean harvest. We urge that the IWC should keep records of all cetacean catches by its member nations.

'For the proper management of cetacean stocks it is essential that all catches are regulated, and in such a way as to take into account small whales caught in the process of other fishery operations. It is also important to regulate shore-based whaling stations in exactly the same way as pelagic fleets, and member nations should not trade in whale products with non-members of the IWC.

'We urge that the commission should accept without serious amendment the advice of its scientists and should not raise quotas for extraneous considerations. Last year's Antarctic catches suggest a shortage of whales: for instance, only 80 per cent of the sei/Bryde's whale quota was taken.

'The Commissioner for Japan has referred to the great sacrifices his country has made to enable the new policy to be carried out. I suggest that this remark goes to the root of the differences between the voluntary bodies and the Commission. In no way can it be regarded as a "great sacrifice" for a community to refrain from eating its seed corn. But this is just what we are doing in failing to conserve the whale stocks of the world.'

What happened to our suggestions?

1. MSY: No action at all. MSY continues to be used.

2. Records of all cetacean catches: No action.

3. Regulation of all catches: No action.

4. Special attention to small whales: No action.

5. Trade in whale products with non-IWC members: All IWC members still do so.

6. Acceptance of scientific advice: This was the one small victory, the halfinch advance of the year. After a great battle, the IWC accepted the Scientific Committee's advice on quotas except for one stock of minke whales. But it is a lamentable state of affairs to have to praise an international body for accepting the advice of its own scientists. 
As a result of this decision, fin whales will be completely protected in both the Southern Hemisphere and the North Pacific, and the only stock that can legally be fished is the small one in the North Atlantic. The details are in the table.

Fin whale

Sei whale

Bryde's whale

Minke whale

Sperm whale

Male

Female
Quotas and Catches 1975/6 and 1976/7

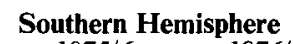

$\begin{array}{cc}1975 / 6 & 1976 / 7 \\ \text { quota catch } & \text { quota }\end{array}$

$220 \quad 206$

$2230 \quad 1820$

nil

6810

5870

4870 nil

6034

nil

1863

nil
8900

4022

3024

3894

897

\section{North Pacific}

$1975 / 6 \quad 1976 / 7$

quota catch quota

1363 nil nil

nil

nil

nil

nil

1000

5200

3100
North Atlantic

$1975 / 6 \quad 1976 / 7$

quota quota

$363 \quad 344$

$2550 \quad 2483$

All those nils, coupled with the continued downward spiral of both quotas and catches, are the highest possible condemnation of the bad management of the International Whaling Commission. Had the commission listened to its scientists twenty years ago, there could have been a flourishing whaling industry today, instead of a dying one.

Next year's meeting is at Canberra, Australia.

\section{Marine Mammals and Man}

The current generation gap in conservation seems to lie between 'old-timers' who concentrate on species studies and the up and coming scientists who are increasingly conscious of the interdependence of all living things and prefer to study ecosystems. This was conspicuous at the meeting at Bergen, Norway, in September 1976, when some 200 marine mammal ecologists, biostatisticians and other specialists assembled from all five continents for a Scientific Consultation on Marine Mammals, sponsored by FAO. The aim of this meeting was to get as complete a picture as possible of the status of the world's whales, dolphins, seals, marine otters, dugongs and manatees, their importance as a resource and how their stocks can be conserved. The final result will not be known until the publication of the report, early in 1977, of the working party which after the conference retired to an island retreat to digest the reports of the meeting's 23 working groups, under the guidance of Dr Sidney Holt, director of the FAO/UNEP Marine Mammals Project in Malta, whose brain-child the whole exercise was.

Almost every species of marine mammal is to some degree threatened by man's activities, whether by direct commercial exploitation, as for whales and seals, or by killing because they directly compete with man for seafood, as with seals and otters, or even purely incidentally by being caught in fish nets, as with dolphins. DDT and dieldrin concentrations in dolphin blubber, combined with the effects of such chemicals in the marine environment as a whole, point up the pollution threat, and the general availability of firearms and motor-boats has given a new meaning to subsistence hunting by Inuit (Eskimo) and other peoples dependent on wild food resources. Loss of habitat, except 